\title{
Mechanisms of dyspnoea relief and improved exercise endurance after furosemide inhalation in COPD
}

\author{
D Jensen, K Amjadi, V Harris-McAllister, K A Webb, D E O’Donnell
}

- Additional data are published online only at http://thorax.bmj. com/content/vol63/issue7

Respiratory Investigation Unit, Department of Medicine,

Queen's University, Kingston, Ontario, Canada

Correspondence to: Dr Denis E O’Donnell,

Respiratory Investigation Unit, Department of Medicine

Queen's University, Kingston, Ontario, Canada K7L 3N6; odonnell@queensu.ca

Presented in part at the ALA/ ATS International Conference, San Diego, May 2006 (Amjadi K, Harris-McAllister VL, Webb KA, et al. Mechanisms of exertional dyspnea relief following nebulised furosemide in patients with COPD. Proc Am Thorac Soc 2006;3:A225.)

Received 5 July 2007 Accepted 16 January 2008 Published Online First

1 February 2008

\section{ABSTRACT}

Background: This study examined the effects of inhaled furosemide on the ventilatory and perceptual response to high-intensity constant-load cycle exercise in chronic obstructive pulmonary disease (COPD).

Methods: In a randomised, double-blind, placebocontrolled, crossover study, 20 patients with COPD (mean (SD) forced expiratory volume in 1 s 45 (15)\% predicted) received either nebulised furosemide $40 \mathrm{mg}$ or placebo on two separate days. Thirty minutes after each treatment, patients performed pulmonary function tests and a symptom-limited cycle exercise test at $75 \%$ of their maximum incremental work rate. Changes in spirometry, plethysmographic lung volumes, dynamic operating lung volumes, ventilation, breathing pattern, cardiovascular function, dyspnoea intensity and exercise endurance time were compared between treatments.

Results: Compared with placebo, treatment with furosemide resulted in a mean (SD) decrease in dyspnoea intensity at the highest equivalent exercise time (ie, isotime for each patient) of 0.9 (1.0) Borg units $(p<0.01)$ and an increase in exercise endurance time of 1.65 (0.63) $\min (p<0.05)$. These improvements were associated with increases in dynamic inspiratory capacity, tidal volume and mean tidal expiratory flow rates at isotime $(p<0.01)$. The eight patients whose exercise endurance time improved by $>1$ min had greater changes in operating lung volumes $(p<0.05)$, submaximal oxygen pulse $(p<0.05)$ and oxygen uptake $(p=0.05)$ than those in whom exercise endurance time did not improve.

Conclusion: Alleviation of exertional dyspnoea after single-dose furosemide inhalation in COPD is multifactorial but improvements in dynamic ventilatory mechanics are contributory in some individuals.

Perceived respiratory difficulty (dyspnoea) and activity limitation are the dominant symptoms of chronic obstructive pulmonary disease (COPD) and contribute importantly to perceived poor health-related quality of life in this population. ${ }^{1}$ Traditionally, efforts to alleviate dyspnoea have largely focused on improving dynamic ventilatory mechanics, reducing ventilatory demand, or both of these in combination..$^{2-8}$ However, recent studies have indicated that it may be possible to reduce the perception of exertional dyspnoea and improve exercise tolerance by altering the activity of vagal pulmonary afferents. In this regard, several published studies have found that inhalation of nebulised furosemide, a powerful loop diuretic known to modulate the activity of sensory afferents in the lungs and airways of laboratory animals, ${ }^{910}$ alleviates the sensation of dyspnoea provoked by different respiratory stimuli applied experimentally in healthy humans. ${ }^{11-13}$ Ong et a $l^{14}$ showed that inhaled furosemide reduced dyspnoea intensity at a standardised time during constant work rate cycle exercise but not during incremental exercise in patients with COPD. A more recent study by Laveneziana et a $l^{15}$ also found no effect on respiratory sensation during incremental exercise with simulated expiratory flow limitation in healthy humans. While the study by Ong et al suggested that altered vagal afferent activity in response to topical furosemide directly and independently influenced the intensity and quality of dyspnoea in COPD, these authors did not conclusively rule out the possible simultaneous effects of inhaled furosemide on ventilatory demand and/or dynamic ventilatory mechanics. In particular, it remains unclear whether inhalation of furosemide, by altering vagal pulmonary afferent activity and reducing cholinergic tone of airway smooth muscle, can improve dynamic airway function (ie, reduce dynamic hyperinflation) and in this manner contribute to exertional dyspnoea relief. It is also possible that inhaled furosemide may affect the cardiovascular response to exercise by either reducing dynamic pulmonary hyperinflation or by direct diuretic effects.

The purpose of this study was therefore to determine if the reduction in exertional dyspnoea ratings following inhalation of furosemide was associated with improvements in ventilatory mechanics, ventilatory demand and/or cardiovascular function or was independent of these mechanisms. Our hypothesis was that improvement in exertional dyspnoea and exercise endurance in response to treatment with inhaled furosemide will be associated with a bronchodilator action of this medication. In a randomised, double-blind, placebo-controlled crossover study, we therefore compared the effects of inhaled furosemide and placebo on dyspnoea intensity, airway function, ventilation, breathing pattern, dynamic operating lung volumes, pulmonary gas exchange, cardiovascular function and exercise endurance during high-intensity constant-load exercise in COPD.

\section{METHODS}

\section{Subjects}

Subjects included clinically stable patients with COPD who were $>40$ years of age with a cigarette smoking history of $\geqslant 20$ pack-years, forced expiratory volume in $1 \mathrm{~s}\left(\mathrm{FEV}_{1}\right) \leqslant 70 \%$ predicted, $\mathrm{FEV}_{1} /$ forced vital capacity (FVC) $<70 \%$ and a modified 
baseline dyspnoea index focal score of $\leqslant 6 .{ }^{16}$ Patients were excluded if they had significant diseases other than COPD that could contribute to dyspnoea and exercise limitation; a history of asthma, atopy, nasal polyps; exercise-induced arterial blood oxygen desaturation to $<80 \%$ on room air; or were allergic to sulfa drugs.

\section{Study design}

After giving written informed consent, patients completed (1) an initial screening visit to determine eligibility for the study; (2) a second visit designed to familiarise patients with all tests that would be performed during subsequent treatment visits; and (3) two treatment visits randomised to order, conducted 2-10 days apart. Visit 1 included a thorough medical history, clinical assessment, chronic dyspnoea evaluation, complete pulmonary function testing and a symptom-limited incremental cycle exercise test. Visit 2 included pulmonary function tests and a constant-load cycle exercise test. After randomisation of treatments (visits 3 and 4), baseline pulmonary function tests were performed before patients inhaled a $4 \mathrm{ml}$ solution containing either furosemide $40 \mathrm{mg}(10 \mathrm{mg} / \mathrm{ml})$ or placebo $(0.9 \%$ saline), administered by means of a jet nebuliser (Parimaster compressor with Pari LC Jet+ nebuliser; PARI Respiratory Equipment, Richmond, VA, USA) with subjects breathing spontaneously for $15 \mathrm{~min}$ using a facemask. Approximately $30 \mathrm{~min}$ after inhalation of either furosemide or placebo, subjects performed pulmonary function tests followed by a symptomlimited constant-load cycle exercise test at $75 \%$ of their maximal incremental work rate. Before each visit, subjects were asked to withdraw from short-acting $\beta_{2}$ agonists $(4 \mathrm{~h})$, short-acting anticholinergics $(6 \mathrm{~h})$, long-acting $\beta_{2}$ agonists (12 h), longacting anticholinergics $(24 \mathrm{~h})$, short-acting theophyllines $(24 \mathrm{~h})$ and long-acting theophyllines (48 h). Subjects avoided caffeine and heavy meals for at least $4 \mathrm{~h}$ before testing and avoided alcohol and major physical exertion entirely on visit days. All visits were conducted at the same time of day for each subject.

\section{Pulmonary function testing}

Pulmonary function tests, including routine spirometry and constant-volume body plethysmography, were conducted in accordance with recommended techniques ${ }^{17}{ }^{18}$ by use of automated equipment (Vmax 229d with Autobox 6200 D SensorMedics, Yorba Linda, CA, USA). Measurements were expressed as percentages of predicted normal values; ${ }^{19-21}$ predicted normal inspiratory capacity (IC) was calculated as predicted total lung capacity (TLC) minus predicted functional residual capacity (FRC).

\section{Cardiopulmonary exercise testing}

Symptom-limited exercise tests were conducted on an electronically braked cycle ergometer (Ergoline 800S; SensorMedics) by use of a cardiopulmonary exercise testing system (Vmax229d; SensorMedics) as previously described..$^{5-7}$ Incremental exercise testing was performed at visit 1 and consisted of a steady-state resting period of at least $3 \mathrm{~min}$ followed by $1 \mathrm{~min}$ of unloaded pedalling with subsequent increases in work rate in stepwise increments of $10 \mathrm{~W}$ each minute, starting at $10 \mathrm{~W}$. Maximal work rate (Wmax) was defined as the highest work rate that the subject was able to maintain for at least $30 \mathrm{~s}$. Constant-load exercise tests consisted of a steady-state resting period, a $1 \mathrm{~min}$ period of unloaded pedalling, then an immediate stepwise increase in work rate to $75 \% \mathrm{Wmax}$ (rounded up to the nearest
$5 \mathrm{~W}$ ) which was maintained until the point of symptom limitation; endurance time was defined as the duration of loaded pedalling.

Measurements were collected at rest and during exercise while subjects breathed through a mouthpiece and a low resistance flow transducer with nasal passages occluded by a noseclip. Measurements included the following: cardiopulmonary and breathing pattern parameters (minute ventilation (VE), oxygen uptake $\left(\mathrm{VO}_{2}\right)$, carbon dioxide production $\left(\mathrm{V}^{\circ} \mathrm{O}_{2}\right)$, endtidal carbon dioxide partial pressure $\left(\mathrm{PeTCO}_{2}\right)$, tidal volume $(\mathrm{Vt})$, breathing frequency $\left(\mathrm{f}_{\mathrm{R}}\right)$, inspiratory $(\mathrm{TI})$ and expiratory time (TE), inspiratory duty cycle (TI/TTOT), mean inspiratory (Vt/TI) and expiratory flow $(\mathrm{Vt} / \mathrm{TE})$ ) were collected on a breath-by-breath basis and compared with predicted normal values; ${ }^{22}$ oxygen saturation $\left(\mathrm{SpO}_{2}\right)$ was measured by pulse oximetry; heart rate was measured by 12-lead ECG; blood pressure was measured by auscultation of the right brachial artery using a sphygmomanometer with an arm cuff; intensity of dyspnoea (breathing discomfort) and leg discomfort was assessed using the 10-point Borg scale $e^{23}$ at rest, during the last 30 s of every 1 min interval during exercise and at end of exercise; operating lung volumes (end inspiratory and end expiratory lung volumes (EILV, EELV)) were derived from IC manoeuvres ${ }^{724}$ performed at rest, within the last $30 \mathrm{~s}$ period of each $2 \mathrm{~min}$ interval during exercise and at end of exercise; and the reason(s) for stopping exercise were recorded.

All breath-by-breath measurements were averaged in $30 \mathrm{~s}$ intervals throughout each test stage (ie, rest, exercise and recovery). Cardiorespiratory measurements collected over the first $30 \mathrm{~s}$ period of every second minute during exercise were linked with symptom ratings and IC measurements collected in the latter $30 \mathrm{~s}$ of the respective minute (to avoid contamination of averaged breath-by-breath data surrounding IC manoeuvres). Three main time points were used for evaluation of exercise parameters: pre-exercise rest, isotime and peak exercise. Preexercise rest was defined as the steady state period after at least 3 min of breathing on the mouthpiece while seated at rest before the start of exercise; cardiorespiratory parameters were averaged over the last $30 \mathrm{~s}$ of this period and IC measurements for this period were collected during breathing on the same circuit immediately after completion of the quiet breathing period. Isotime was defined as the highest equivalent exercise time achieved during each of the constant-load tests performed by a given subject, rounded down to the nearest whole minute. Peak exercise was defined as the last $30 \mathrm{~s}$ of loaded pedalling; cardiorespiratory parameters were averaged over this time period and IC measurements and Borg ratings of dyspnoea and leg discomfort were collected immediately after the end of this period.

\section{Statistical analysis}

The sample size of 20 subjects provides the power (80\%) to detect a significant difference in dyspnoea intensity measured at a standardised time during exercise based on a relevant difference in Borg dyspnoea ratings of \pm 1 Borg unit, a standard deviation based on values established in our laboratory for a similar group of 105 patients with COPD, ${ }^{24} \alpha=0.05$ and a twotailed test of significance. Treatment responses were compared by paired $t$ tests with appropriate Bonferroni adjustments for multiple comparisons. Reasons for stopping exercise were analysed using the Fisher exact test. Pearson correlations were used to establish associations between standardised (isotime) measurements of exertional dyspnoea intensity and relevant independent variables; forward stepwise multiple regression 
Table 1 Characteristics of study subjects

\begin{tabular}{|c|c|}
\hline$M: F(n)$ & $11: 9$ \\
\hline Age (years) & $61.4(8.3)$ \\
\hline Height (cm) & $168.0(9.6)$ \\
\hline Weight (kg) & $79.9(20.9)$ \\
\hline Body mass index $\left(\mathrm{kg} / \mathrm{m}^{2}\right)$ & $28.4(7.9)$ \\
\hline Smoking history (pack-years) & $47.7(20.2)$ \\
\hline Duration of COPD (years) & $9.4(7.8)$ \\
\hline $\begin{array}{l}\text { Modified baseline dyspnoea index } \\
\text { (focal score) }\end{array}$ & $5.8(0.7)$ \\
\hline $\mathrm{FEV}_{1}(\mathrm{I})$ & $1.16(0.36)$ \\
\hline $\mathrm{FEV}_{1}(\%$ predicted) & $45(15)$ \\
\hline $\mathrm{FEV}_{1} / \mathrm{FVC}(\%)$ & $42(10)$ \\
\hline $\mathrm{FEV}_{1} / \mathrm{FVC}(\%$ predicted) & $59(14)$ \\
\hline FVC (I) & $2.78(0.63)$ \\
\hline FVC (\% predicted) & $75(14)$ \\
\hline IC (I) & $2.19(0.53)$ \\
\hline IC (\% predicted) & $82(24)$ \\
\hline FRC (I) & $4.34(1.60)$ \\
\hline FRC (\% predicted) & $134(37)$ \\
\hline RV (I) & $3.45(1.44)$ \\
\hline RV (\% predicted) & $162(59)$ \\
\hline sRaw (cm $\mathrm{H}_{2} \mathrm{O} . \mathrm{s}$ ) & $28.1(13.7)$ \\
\hline sRaw (\% predicted) & $667(312)$ \\
\hline $\mathrm{TLCO}(\mathrm{ml} / \mathrm{min} / \mathrm{mm} \mathrm{Hg})$ & $15.1(4.2)$ \\
\hline TLCo (\% predicted) & $70(17)$ \\
\hline
\end{tabular}

analysis was carried out with significant variables and relevant covariates. A $p<0.05$ significance level was used for all analyses. Results are reported as mean (SD) unless otherwise specified.

A post hoc subgroup analysis was conducted after examination of the data showed that eight subjects had a clear furosemide-induced improvement in exercise endurance time by $>1$ min (responders) compared with the remaining subjects who had no improvement in exercise endurance time (nonresponders). Within- and between-group comparisons were made using a two-way repeated measures analysis of variance.

\section{RESULTS}

Twenty subjects with moderate to severe COPD and significant chronic activity-related dyspnoea completed the study (table 1); an additional subject with severe disease was withdrawn from the study due to worsening of COPD symptoms. CT scans of the chest were available for all subjects allowing examination of the presence of emphysema; 10 subjects had moderate to severe emphysema, 9 of these with an upper lobe predominance; the remaining 10 subjects only had minimal airspace dilatation.

Treatment order was balanced such that nine $(45 \%)$ were randomised to receive treatment with furosemide first. There were no pre-dose differences in spirometric parameters or plethysmographic lung volumes between placebo and furosemide treatment visits, other than a significantly $(p=0.033)$ higher peak expiratory flow rate (PEFR) on the furosemide treatment day (table 2). However, this difference in PEFR was maintained after furosemide and resulted in no significant treatment response compared with placebo.

Post-treatment changes in resting pulmonary function are shown in table 2 . There were no significant pre- to post-dose differences in response to treatment with placebo. After furosemide, measurements of forced spirometry did not change; TLC did not change; slow vital capacity (SVC) and inspiratory capacity (IC) increased; and FRC and residual volume (RV) decreased. Despite these within-treatment differences, the only significant treatment response after furosemide compared with placebo was in the pre- to post-dose change in SVC (mean difference $0.131,95 \%$ confidence interval (CI) 0.05 to 0.21 , $\mathrm{p}=0.002$ ); the treatment response in RV (mean difference $-0.141,95 \%$ CI -0.30 to $0.01, p=0.060$ ) reflected that of SVC since TLC did not change. The increase in SVC (decrease in RV) after furosemide may be explained in part by the prolongation of total expiratory time by an average of $1.7 \mathrm{~s}(\mathrm{p}=0.08)$ during the vital capacity manoeuvre $(r=0.52, p=0.014)$.

\section{Treatment responses to constant-load cycle exercise}

Exercise endurance time increased by a mean (SD) of 1.65 (2.9) $\min (16(21) \%)$ after treatment with furosemide compared with placebo $(p=0.017$, paired t test; $p=0.004$, Wilcoxon signed rank test); endurance time increased by $>1 \mathrm{~min}$ in eight subjects (mean (SD) increase of 4.4 (2.2) min), changed by less

Table 2 Pulmonary function tests

\begin{tabular}{|c|c|c|c|c|}
\hline & \multicolumn{2}{|l|}{ Placebo } & \multicolumn{2}{|l|}{ Furosemide } \\
\hline & Pre-dose & $\Delta$ Post-dose & Pre-dose & $\Delta$ Post-dose \\
\hline $\mathrm{FEV}_{1}(\mathrm{I})$ & $1.16(0.37)$ & $-0.02(0.11)$ & $1.19(0.37)$ & $0.02(0.08)$ \\
\hline $\mathrm{FEV}_{1} / \mathrm{FVC}(\%)$ & $42(9)$ & $-0.9(2.2)$ & $42(9)$ & $-0.0(4.7)$ \\
\hline FVC (I) & $2.79(0.65)$ & $0.01(0.19)$ & $2.84(0.73)$ & $0.06(0.29)$ \\
\hline PEFR (I/s) & $3.95(0.97)$ & $-0.03(0.35)$ & $4.17(1.17)^{*}$ & $-0.04(0.30)$ \\
\hline $\mathrm{FEF}_{25-75 \%}(\mathrm{l} / \mathrm{s})$ & $0.36(0.12)$ & $-0.03(0.07)$ & $0.36(0.15)$ & $-0.01(0.06)$ \\
\hline IC (I) & $2.18(0.54)$ & $0.01(0.11)$ & $2.23(0.56)$ & $0.08(0.18) \dagger$ \\
\hline SVC (I) & $3.07(0.81)$ & $-0.00(0.20)$ & $3.08(0.74)$ & $0.13(0.18) \dagger$ \\
\hline FRC (I) & $4.35(1.61)$ & $-0.00(0.26)$ & $4.34(1.57)$ & $-0.08(0.14) \dagger$ \\
\hline RV (I) & $3.45(1.44)$ & $0.01(0.38)$ & $3.49(1.31)$ & $-0.13(0.20) \dagger$ \\
\hline TLC (I) & $6.53(1.62)$ & $0.01(0.23)$ & $6.57(1.57)$ & $-0.00(0.18)$ \\
\hline Raw $\left(\mathrm{cm} \mathrm{H} \mathrm{H}_{2} \mathrm{O} / \mathrm{s}\right.$ ) & $5.4(2.3)$ & $0.3(0.7)$ & $5.2(2.3)$ & $-0.2(0.7)$ \\
\hline
\end{tabular}

Values are mean (SD).

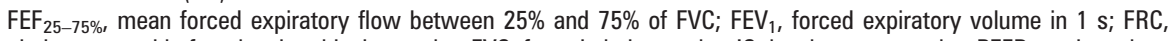

plethysmographic functional residual capacity; FVC, forced vital capacity; IC, inspiratory capacity; PEFR, peak expiratory flow rate; $\triangle$ Post-dose, change from pre- to post-dose; Raw, airway resistance; RV, residual volume; SVC, slow vital capacity; TLC, total lung capacity.

${ }^{*} \mathrm{p}<0.05$ pre-treatment difference; $\uparrow \mathrm{p}<0.05$ post-dose vs pre-dose difference within treatment; $\$ \mathrm{p}<0.05$ difference between acute within-drug treatment responses (post- minus pre-drug). 
Figure 1 Mean (SE) ratings (modified 10-point Borg scale) of dyspnoea intensity during constant-load cycle exercise at $75 \%$ of peak work rate after inhalation of furosemide or placebo. Exertional dyspnoea intensity decreased significantly after furosemide compared with placebo at the highest equivalent isotime measurement $\left({ }^{*} p<0.05\right)$ but was not different between treatments when expressed against ventilation.

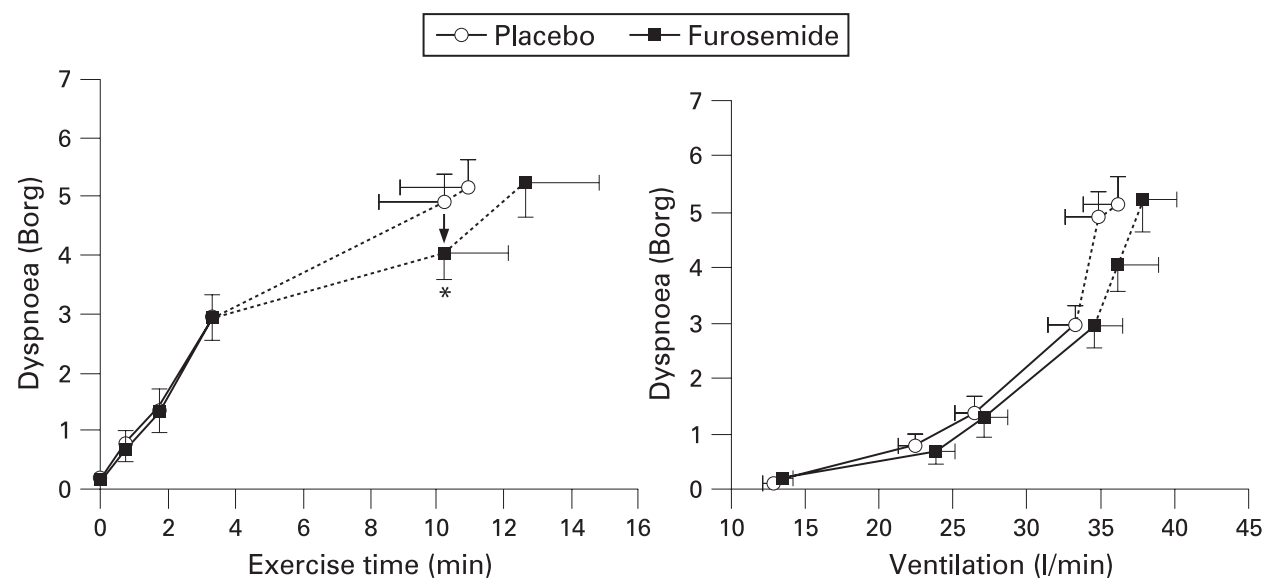

than \pm 1 min in 11 subjects (mean (SD) change of $0.2(1.3)$ min) and decreased by $4 \mathrm{~min}(13 \%)$ in 1 subject who had a very long endurance time of $30 \mathrm{~min}$ after placebo. The distribution of reasons for stopping exercise was different after furosemide than after placebo $(p=0.029)$ : fewer subjects stopped primarily because of dyspnoea ( $25 \%$ vs $35 \%$ ) and more subjects stopped because of leg discomfort ( $50 \%$ vs $40 \%$ ) or a combination of breathing and leg discomfort (25\% vs $10 \%$ ).

Dyspnoea intensity during exercise is shown in fig 1. After treatment with furosemide compared with placebo, dyspnoea intensity decreased by $0.9(1.0)$ Borg units $(p=0.006)$ at isotime (10.2 (8.7) min) during exercise (table 3); in 15 subjects dyspnoea intensity decreased by at least 1 Borg unit, in four subjects the dyspnoea rating did not change and in 1 subject the dyspnoea intensity increased by 2 Borg units. Borg ratings of perceived breathing and leg discomfort were not significantly different at the end of exercise (table 3).

There were no statistically significant treatment differences in pre-exercise resting measurements of breathing pattern, pulmonary gas exchange or cardiovascular function. Measurements at the symptom-limited end point of exercise (peak) are shown in table 3; there were small but significant increases in peak $\dot{V O}_{2}(p=0.012), \quad V O_{2} \quad(p=0.013)$, VE $(p=0.009)$ and $V t / T E(p=0.029)$ after furosemide compared with placebo. Measurements at the highest equivalent isotime during exercise are shown in table 3 ; there were small increases in $\mathrm{Vt}(p=0.038)$, IC $(p=0.028)$ and $V t / T E(p=0.032)$ after treatment with furosemide compared with placebo.

Mean cardiorespiratory responses to exercise after treatment with furosemide and placebo are shown in an online data

Table 3 Post-dose cardiorespiratory and perceptual responses at the highest equivalent isotime and at the symptom-limited peak of constant work rate exercise at 75\% Wmax (53 (4) Watts)

\begin{tabular}{|c|c|c|c|c|}
\hline & \multicolumn{2}{|l|}{ Isotime } & \multicolumn{2}{|l|}{ Peak } \\
\hline & Placebo & Furosemide & Placebo & Furosemide \\
\hline Time (min) & $10.2(8.7)$ & $10.2(8.7)$ & $10.9(9.0)$ & $12.6(10.0)^{*}$ \\
\hline Dyspnoea (Borg) & $4.9(2.1)$ & $4.1(2.2) \dagger$ & $5.2(2.2)$ & $5.2(2.6)$ \\
\hline Leg discomfort (Borg) & $5.6(2.5)$ & $5.0(2.6)$ & $6.3(2.7)$ & $6.3(2.4)$ \\
\hline HR (beats/min) & $115(21)$ & $115(19)$ & $116(19)$ & $116(19)$ \\
\hline $\mathrm{O}_{2}$ pulse (ml/beat) & $9.5(3.1)$ & $9.9(3.7)$ & $9.7(3.2)$ & $10.2(3.1)^{*}$ \\
\hline$\dot{\mathrm{V}}_{2}(\mathrm{ml} / \mathrm{kg} / \mathrm{min})$ & $13.6(3.8)$ & $14.1(3.7)$ & $14.0(3.7)$ & $14.8(3.3)^{*}$ \\
\hline$\dot{\mathrm{V}} \mathrm{CO}_{2}(\mathrm{ml} / \mathrm{kg} / \mathrm{min})$ & $13.2(4.1)$ & $14.0(4.2)^{*}$ & $13.9(4.0)$ & $14.8(3.7)^{*}$ \\
\hline VE (I/min) & $34.8(10.2)$ & $36.2(11.9)$ & $36.1(10.3)$ & $37.9(10.5)^{*}$ \\
\hline Vt (I) & $1.17(0.30)$ & $1.24(0.33)^{*}$ & $1.18(0.30)$ & $1.24(0.31)$ \\
\hline $\mathrm{f}_{\mathrm{R}}$ (breaths/min) & $30.5(7.8)$ & $29.6(7.4)$ & $31.4(8.1)$ & $31.2(7.2)$ \\
\hline $\mathrm{TI}(\mathrm{s})$ & $0.79(0.20)$ & $0.82(0.19)$ & $0.78(0.20)$ & $0.77(0.18)$ \\
\hline TE (s) & $1.29(0.32)$ & $1.30(0.31)$ & $1.28(0.34)$ & $1.27(0.28)$ \\
\hline ТІ/Ттот (\%) & $38.0(4.1)$ & $38.4(4.0)^{*}$ & $38.6(5.4)$ & $38.4(4.2)$ \\
\hline $\mathrm{Vt} / \mathrm{TI}(\mathrm{l} / \mathrm{s})$ & $1.53(0.46)$ & $1.56(0.48)$ & $1.58(0.47)$ & $1.65(0.42)$ \\
\hline $\mathrm{Vt} / \mathrm{TE}(\mathrm{l} / \mathrm{s})$ & $0.94(0.29)$ & $1.00(0.34)^{*}$ & $0.96(0.29)$ & $1.01(0.30)^{*}$ \\
\hline IC (I) & $1.78(0.46)$ & $1.90(0.45)^{*}$ & $1.76(0.43)$ & $1.84(0.47)$ \\
\hline$\Delta \mathrm{IC}$ from rest $(\mathrm{I})$ & $-0.61(0.38)$ & $-0.60(0.47)$ & $-0.61(0.42)$ & $-0.65(0.44)$ \\
\hline IRV (I) & $0.61(0.30)$ & $0.66(0.29)$ & $0.58(0.27)$ & $0.61(0.32)$ \\
\hline $\mathrm{PetCO}_{2}(\mathrm{~mm} \mathrm{Hg})$ & $37.6(3.7)$ & $38.4(4.2)$ & $37.7(4.2)$ & $38.0(4.5)$ \\
\hline $\mathrm{SpO}_{2}(\%)$ & $93.6(2.5)$ & $93.8(2.9)$ & $93.6(2.7)$ & $93.6(3.0)$ \\
\hline
\end{tabular}

Values are mean (SD).

$\mathrm{f}_{\mathrm{R}}$, breathing frequency; HR, heart rate; IC, inspiratory capacity; $\Delta I C$, change in IC from rest (ie, extent of dynamic hyperinflation); IRV, inspiratory reserve volume; $\mathrm{PETCO}_{2}$, partial pressure of end tidal $\mathrm{CO}_{2} ; \mathrm{SpO}_{2}$, oxygen saturation measured by pulse oximetry; $\mathrm{TE}_{2}$ expiratory time; $\mathrm{TI}$, inspiratory tine; $\mathrm{TI} / \mathrm{TTOT}$, inspiratory duty cycle; Ттот, total time; $\mathrm{V}_{\mathrm{CO}_{2}}$, carbon dioxide production; $\mathrm{VE}$, minute ventilation; $\dot{V}_{2}$, oxygen uptake; $\mathrm{Vt}$, tidal volume; $\mathrm{Vt} / \mathrm{TE}$, mean expiratory tidal flow; $\mathrm{Vt} / \mathrm{TI}$, mean inspiratory tidal flow.

${ }^{*} \mathrm{p}<0.05,+\mathrm{p}<0.01$ furosemide vs placebo at same stage of exercise. 

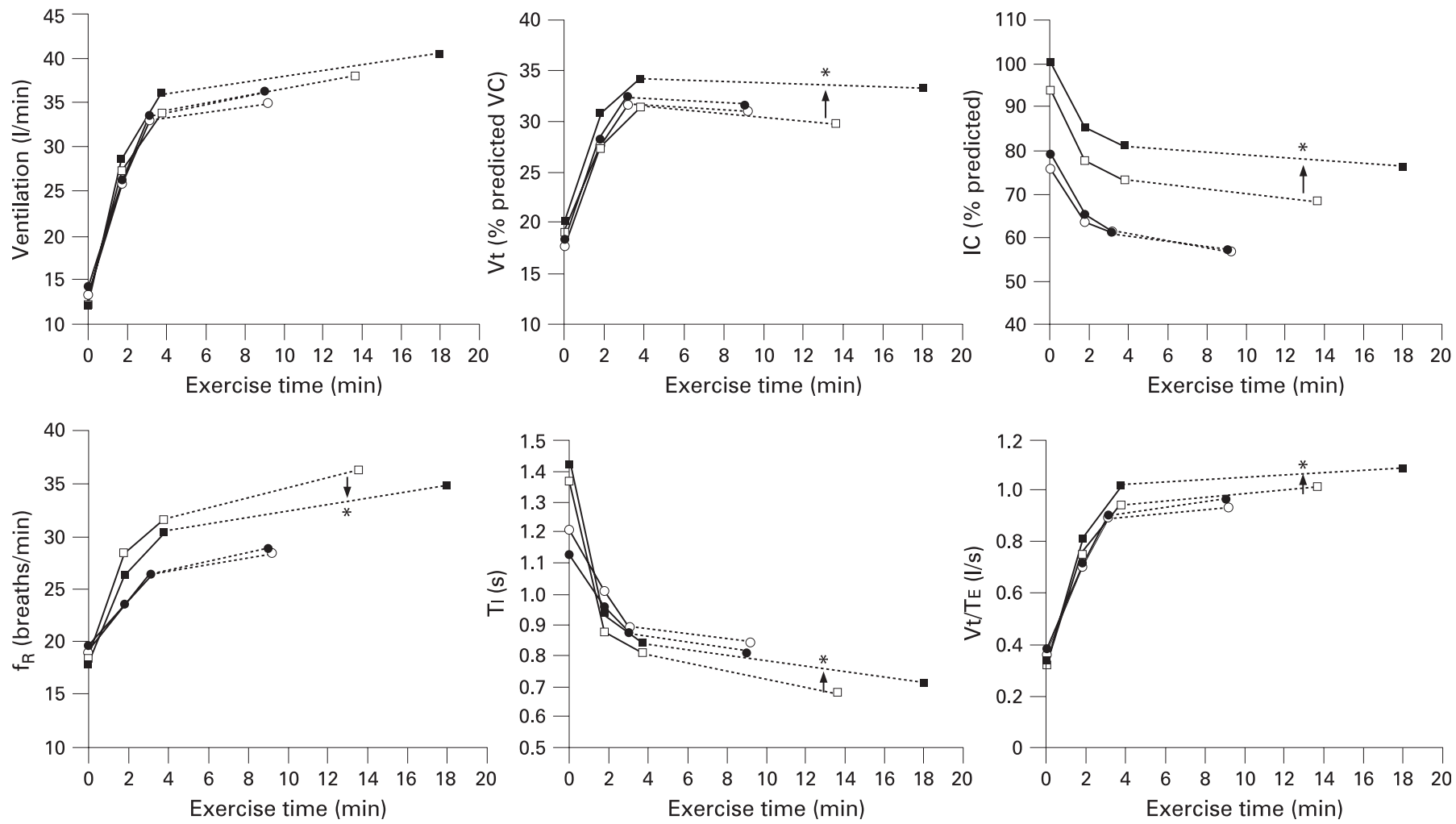

Figure 2 Ventilation, breathing pattern and operating lung volume measurements during constant-load cycle exercise at $75 \%$ of peak work rate after inhalation of furosemide or placebo in the responder $(R)$ and non-responder (NR) subgroups. $f_{R}$, breathing frequency; IC, inspiratory capacity; $\mathrm{TI}$, inspiratory time; VC, vital capacity; Vt, tidal volume; Vt/TE, mean tidal expiratory flow. Data points are mean values at rest, at standardised time points early in exercise and at peak exercise. ${ }^{*} \mathrm{p}<0.05$ placebo vs furosemide at the highest equivalent isotime (indicated by arrows) during exercise.

Figure 3 Intensity of leg discomfort, oxygen pulse, heart rate (HR) and carbon dioxide output $\left(\dot{\mathrm{V}}_{2}\right)$ during constant-load cycle exercise at $75 \%$ of peak work rate after inhalation of furosemide or placebo in the responder $(R)$ and non-responder (NR) subgroups. Data points are mean values at rest, at standardised time points early in exercise and at peak exercise. ${ }^{*} p<0.05$ placebo vs furosemide at the highest equivalent isotime (indicated by arrows) during exercise.

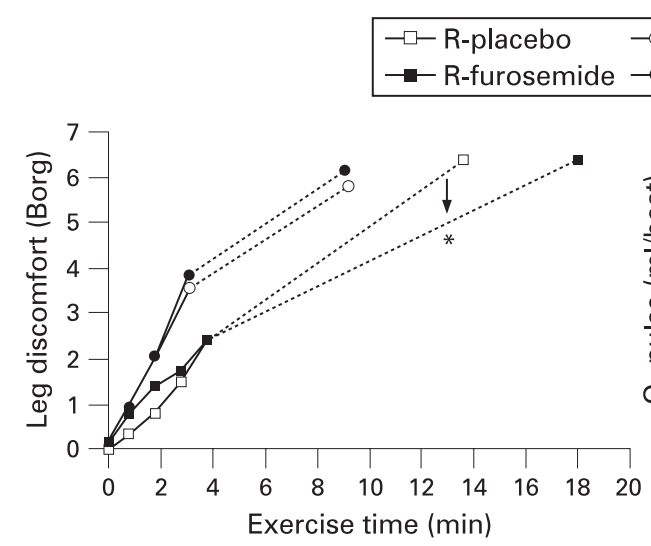

$-\mathrm{O}-\mathrm{NR}$-placebo
- - NR-furosemide
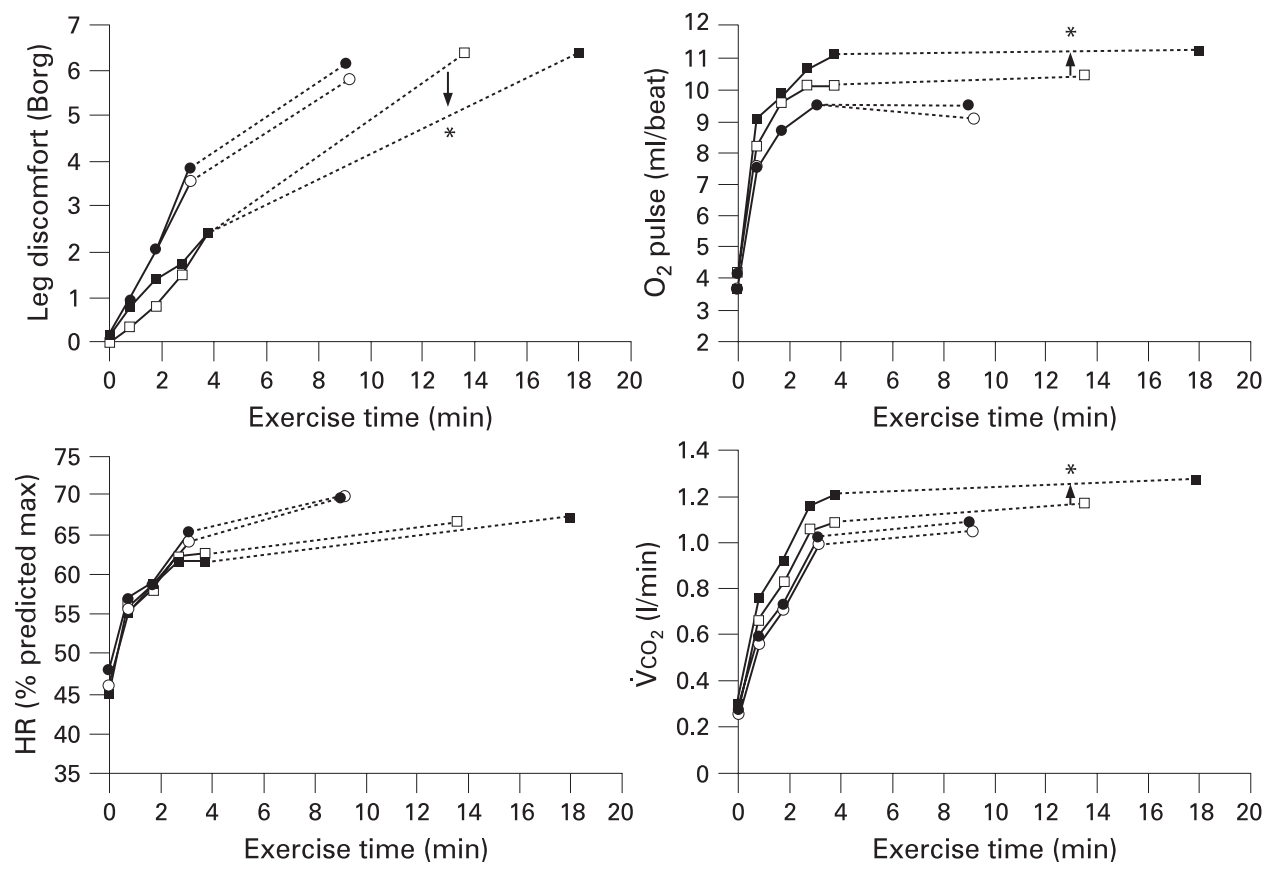
supplement. Breathing pattern was relatively deeper and slower with a small but consistent prolongation of $\mathrm{TI}$ and no significant change in Vt/TI. Dynamic IC increased by approximately 0.121 at rest and throughout exercise after treatment with furosemide compared with placebo; however, exerciseinduced changes in dynamic IC from rest were not significantly different across treatments (table 3). Furosemide had no significant effect on dynamic IRV throughout exercise.

\section{Subgroup analysis}

Baseline pulmonary function showed that responders (subjects with a furosemide-induced improvement in exercise endurance time $>1 \mathrm{~min}$ ) had significantly less severe expiratory airflow limitation and hyperinflation than non-responders (subjects who did not improve exercise endurance time). Mean improvements in exercise endurance and dynamic ventilatory mechanics that were seen in the group as a whole were driven by the changes seen in the responder subgroup (fig 2). Additional cardiovascular responses to inhaled furosemide were uncovered by the subgroup analysis; although heart rate and blood pressure responses to exercise did not change, oxygen pulse increased significantly $(p<0.05)$ at isotime during exercise and at peak exercise (fig 3). There were seven patients in the nonresponder subgroup in whom exercise endurance did not improve but in whom dyspnoea intensity was reduced at isotime during exercise by 1 Borg unit. In these patients there were no changes in cardiovascular measurements or intensity of leg discomfort, and changes in dynamic respiratory mechanics were intermediate to those of the responders but nonsignificant (ie, isotime IC increased by a mean of 0.11 l). Additional information on the subgroup analysis is presented in an online data supplement.

\section{Correlates of improvement}

Intra-subject reductions in dyspnoea at the highest equivalent isotime correlated with concurrent changes in $\mathrm{TI}(\mathrm{r}=-0.78$, $\mathrm{p}<0.0005)$, Vt percentage predicted VC $(\mathrm{r}=-0.61, \mathrm{p}=0.004)$ and IC percentage predicted $(r=-0.46, p=0.040)$. Covariates of this improvement included baseline PEFR $(r=-0.66$, $p=0.002), \quad$ sRaw $\quad(r=0.64, \quad p=0.002), \quad$ IC $\quad(r=-0.49$, $\mathrm{p}=0.029), \quad \mathrm{FEV}_{1} \quad(\mathrm{r}=-0.49, \quad \mathrm{p}=0.030)$ and $\quad \mathrm{FEV}_{1} / \mathrm{FVC}$ $(\mathrm{r}=-0.45, \mathrm{p}=0.049)$, all expressed as percentage predicted. Using stepwise multiple regression analysis, $80 \%$ of the variance in the change in dyspnoea intensity at isotime was explained by the combination of isotime changes in $\mathrm{TI}, \mathrm{Vt} / \mathrm{TE}$ and $\mathrm{Vt}$ $\left(r^{2}=0.796\right)$. Increased exercise endurance time correlated significantly with the decreased dyspnoea intensity at isotime $(\mathrm{r}=-0.45, \mathrm{p}=0.047)$.

\section{DISCUSSION}

The main findings of this study are as follows: (1) single-dose inhalation of nebulised furosemide was associated with reductions in the intensity of exertional dyspnoea with attendant improvement in exercise endurance time; (2) inhaled furosemide was associated with minor but consistent changes in slow vital capacity at rest, together with small mean changes in IC and breathing pattern during high-intensity constant-load exercise; (3) improvements in exertional dyspnoea (and exercise endurance) occurred in the absence of significant changes in ventilatory demand and pulmonary gas exchange during exercise and correlated with improved volume and timing components of breathing; and (4) subgroup analysis showed that individuals in whom exercise endurance improved the most after furosemide inhalation had greater improvements in airway and cardiovascular function during exercise.

The patients in this study had moderate to severe COPD with severe ventilatory constraints during exercise and clinically significant chronic activity-related dyspnoea. Consistent with the results of a previous study in COPD by Ong et al,,${ }^{14}$ we found that single-dose inhalation of nebulised furosemide was associated with a significant decrease in ratings of dyspnoea intensity at a standardised time during exercise by an average of 0.9 Borg units $(p<0.01)$; dyspnoea intensity was reduced by at least 1 Borg unit in 15 of 20 patients at isotime after treatment with inhaled furosemide compared with placebo. This is the first study, however, to demonstrate significant improvement in exercise endurance time (by an average of $1.65 \mathrm{~min}(16 \%)$; $\mathrm{p}<0.02)$ after treatment with inhaled furosemide compared with placebo in this population. Improved endurance time correlated with reduced dyspnoea intensity ratings at isotime during exercise. Differences in our results with those of Ong et al probably reflect differences in study protocols. For example, incremental and constant-load cycle exercise tests were conducted on separate days in our study to avoid the potentially confounding effects of peripheral locomotor muscle fatigue on measures of exercise endurance. ${ }^{25} 26$

We considered the following potential mechanisms of dyspnoea relief during exercise after treatment with inhaled furosemide: (1) reduced intrinsic mechanical loading of the inspiratory muscles secondary to improved airway function and reduced dynamic hyperinflation; (2) reduced ventilatory demand; (3) furosemide-induced alterations in vagal pulmonary afferent activity, independent of changes in dynamic ventilatory mechanics and/or cardiovascular function; and (4) any combination of the above.

An earlier study in COPD observed a very small but statistically significant bronchodilator effect after inhalation of furosemide as evidenced by a change of $0.05 \mathrm{l}(\sim 5 \%)$ in $\mathrm{FEV}_{1} \cdot{ }^{14}$ This is unlikely to be due to a direct effect of furosemide on airway smooth muscle as it has been shown to have no effect on airway contractility in vitro. ${ }^{27}{ }^{28}$ However, there is evidence that inhaled furosemide, by increasing slowly adapting receptor (SAR) activity ${ }^{9}$ and decreasing rapidly adapting receptor (RAR) activity, ${ }^{10}$ may cause reflex bronchodilation secondary to reduced parasympathetic outflow and thus cholinergic tone of airway smooth muscle. ${ }^{29-32}$ We observed no significant change in resting tests of airway function or plethysmographic lung volumes after treatment with inhaled furosemide compared with placebo. This finding is similar to previous studies in healthy subjects ${ }^{12}$ and in subjects with asthma. ${ }^{33}$ Interestingly, furosemide inhalation was associated with a significant increase in SVC by an average of 0.131 . This may be explained, at least in part, by consistent increases in expiratory time during the VC manoeuvre (by an average of $1.7 \mathrm{~s}$ ). Inspection of maximal flow-volume loops and expiratory volume-time plots before and after treatment showed that these were essentially superimposed for each subject. We postulate that this increased ability to tolerate a more prolonged expiration during spirometry may be associated with altered vagal mechanoreceptor input from the airways, as previously described. ${ }^{9} 1013293134$ At isotime during exercise, dynamic IC was increased significantly by an average of 0.121 after furosemide inhalation with no difference in dynamic IRV. Rest-to-peak exercise changes in IC, which reflect the rate of dynamic lung hyperinflation during exercise, were similar across treatments. These small mean changes in exercise IC were approximately $50 \%$ of the change previously seen with various inhaled bronchodilators. ${ }^{4} 5$ Small 
but significant increases in mean expiratory flow (with an unchanged TE) in the setting of a reduced EELV were measured after furosemide, suggesting some attenuation of expiratory flow limitation as an explanation of the increased IC.

Nishino et $a l^{13}$ previously found that VE was significantly reduced in healthy subjects during mechanical loading of the respiratory system at rest after inhaled furosemide compared with placebo, suggesting that furosemide may reduce central ventilatory drive and that this may explain, at least in part, the observed dyspnoea relief. We could find no evidence of reduced ventilatory demand at rest or during exercise when patients were randomised to treatment with inhaled furosemide. In fact, ventilation tended to increase after furosemide $(p=0.066)$, mainly due to an increase in $\mathrm{Vt}$, and did so in the absence of a concomitant increase in dyspnoea ratings. Furthermore, there were no differences in the pulmonary gas exchange responses to exercise that would account for the observed dyspnoea relief. The increase in $\mathrm{Vt}$ at a standardised time during exercise following inhaled furosemide could be accommodated in these hyperinflated patients as a result of the simultaneous recruitment of IC (without further reducing dynamic IRV). Interestingly, we found that $80 \%$ of the variance in postfurosemide improvements in dyspnoea ratings (at isotime) was explained by concomitant increases in $\mathrm{TI}, \mathrm{Vt} / \mathrm{TE}$ and $\mathrm{Vt}$. We speculate that these changes in the volume and timing components of breathing could represent the effects of inhaled furosemide on dynamic ventilatory mechanics (increased Vt/TE and reduced EELV).

A subanalysis which compared responses in the group of patients in whom exercise endurance was improved while receiving furosemide $(n=8)$ with those who did not revealed that the former had significantly greater treatment effects on dynamic ventilatory mechanics and on oxygen transport as indicated by consistent improvements in the submaximal oxygen pulse, $\mathrm{VO}_{2}$ and $\mathrm{V}_{\mathrm{CO}_{2}}$. Those who showed the largest improvements in exercise endurance and dynamic airway function during exercise had less severe COPD at baseline, but had similar flow and volume responses to furosemide at rest as the non-responders. To the extent that pulmonary vagal reflexes become more attenuated as the severity of COPD progresses, the relatively reduced bronchodilation effect in those with the worst disease may reflect this phenomenon. ${ }^{35} 36$

The improvements in submaximal metabolic parameters and oxygen pulse, together with significantly reduced perceived leg discomfort, point to possible improvements in cardiovascular performance. It is unclear whether this improvement relates to improved cardiopulmonary interactions as a result of mechanical unloading of the ventilatory muscles (as previously described with bronchodilator therapy) $)^{37}$ or to a direct "systemic" effect of furosemide on cardiac function. Moosavi et $a l^{12}$ showed that inhaled furosemide ( $40 \mathrm{mg}$ ) relieved the sensation of experimentally-induced dyspnoea ("air hunger") for $\sim 1 \mathrm{~h}$ after its administration in healthy subjects at rest; however, clear evidence of a systemic diuretic effect was only apparent $>1 \mathrm{~h}$ after treatment. Inhaled furosemide, whose salutary effects on exertional dyspnoea were evident within $1 \mathrm{~h}$ of dosing, had no demonstrable effect on heart rate or blood pressure responses at rest or during exercise in our study. It therefore seems unlikely that improvement in oxygen pulse (an imprecise surrogate for stroke volume) and $\mathrm{VO}_{2}$ at isotime during exercise was the result of a systemic diuretic effect. Nonetheless, this possibility could not be definitively ruled out in this study.
The question arises whether the relief of exertional dyspnoea observed in this study is due to a local effect of inhaled furosemide on vagal sensory afferent discharge independent of reflex anticholinergic bronchodilation, as has previously been postulated in both animal and human studies. ${ }^{9-14}$ The possibility of such direct vagal sensory influences would be supported by the finding of consistent improvements of dyspnoea at a standardised exercise stimulus with concomitant changes in breathing pattern (ie, TI prolongation) in the absence of any change in dynamic ventilatory mechanics, metabolic or cardiovascular function. ${ }^{38-40}$ Such was not the case in the present study. However, our results do indicate that perceptual responses to inhaled furosemide were variable across patients and that those who benefited most were more likely to have the greatest bronchodilator effect during exercise. The seven subjects who experienced exertional dyspnoea relief in the absence of improvement in exercise endurance time tended to have inconsistent smaller improvements in dynamic IC but had no changes in cardiovascular responses or perceived leg discomfort during exercise. The relative importance of direct vagal effects on respiratory sensation (independent of any bronchodilator action) could not therefore be ascertained.

In conclusion, nebulised furosemide was associated with consistent and potentially clinically important improvements in dyspnoea intensity and exercise endurance in patients with advanced COPD. These acute improvements in exertional dyspnoea are multifactorial and could not be explained by alterations in ventilatory demand or pulmonary gas exchange. Improvements in airway function and dynamic ventilatory mechanics occurred in association with dyspnoea relief after inhaled furosemide. This is supported by the strong correlation between a reduction in dyspnoea and changes in the volume and timing components of breathing during exercise. The magnitude of the benefit of inhaled furosemide in this shortterm study is similar to that reported following acute administration of a number of established treatments in advanced COPD..$^{2-7}$ This study therefore supports the rationale for future assessment of inhaled furosemide as a therapeutic intervention for patients with COPD with incapacitating dyspnoea.

Funding: This study was funded in part by an Ontario Thoracic Society Block Term Grant. KA received a John Alexander Stewart Research Fellowship from the Department of Medicine, Queen's University. DJ was supported by an Ontario Graduate Scholarship.

Competing interests: None.

Ethics approval: This study was approved by the local university/hospital research ethics committee.

\section{REFERENCES}

1. Jones PW. Health status measurement in chronic obstructive pulmonary disease. Thorax 2001;56:880-7.

2. Peters MM, Webb KA, O'Donnell DE. Combined physiological effects of bronchodilators and hyperoxia on exertional dyspnea in normoxic COPD. Thorax 2006;61:559-67.

3. Somfay A, Porszasz SML, Casaburi R. Dose-response effect of oxygen on hyperinflation and exercise endurance in nonhypoxaemic COPD patients. Eur Respir J 2001;18:77-84

4. O'Donnell DE, Flüge T, Gerken F, et al. Effects of tiotropium on lung hyperinflation, dyspnea and exercise tolerance in COPD. Eur Respir J 2004;23:832-40.

5. O'Donnell DE, Voduc N, Fitzpatrick M, et al. Effect of salmeterol on the ventilatory response to exercise in COPD. Eur Respir J 2004;24:86-94.

6. O'Donnell DE, D'Arsigny C, Webb KA. Effects of hyperoxia on ventilatory limitation during exercise in advanced COPD. Am J Respir Crit Care Med 2001;163:892-8.

7. O'Donnell DE, Lam M, Webb KA. Measurement of symptoms, lung hyperinflation and endurance during exercise in chronic obstructive pulmonary disease. Am J Respir Crit Care Med 1998:158:1557-65. 
8. O'Donnell DE, Webb KA, Bertley JC, et al. Mechanisms of relief of exertional breathlessness following unilateral bullectomy and lung volume reduction surgery in emphysema. Chest 1996;110:18-27.

9. Sudo T, Hayashi F, Nishino T. Responses of tracheobronchial receptors to inhaled furosemide in anesthetized rats. Am J Respir Crit Care Med 2000;162:971-5.

10. Sant'Ambrogio FB, Sant'Ambrogio G, Anderson JW. Effect of furosemide on the response of laryngeal receptors to low-chloride solutions. Eur Respir J 1993;6:1151-5.

11. Minowa $\mathbf{Y}$, Ide $\mathrm{T}$, Nishino $\mathrm{T}$. Effects of inhaled furosemide on $\mathrm{CO}_{2}$ ventilatory responsiveness in humans. Pulm Pharmacol Ther 2002;15:363-8.

12. Moosavi SH, Binks AP, Lansing RW, et al. Effect of inhaled furosemide on air hunger induced in healthy humans. Respir Physiol Neurobiol 2007;156:1-8.

13. Nishino T, Ide T, Sudo T, et al. Inhaled furosemide greatly alleviates the sensation of experimentally induced dyspnea. Am J Respir Crit Care Med 2000;161:1963-7.

14. Ong KC, Kor AC, Chong WF, et al. Effects of inhaled furosemide on exertional dyspnea in chronic obstructive pulmonary disease. Am J Respir Crit Care Med 2004;169:1028-33.

15. Laveneziana P, Galarducci A, Binazzi B, et al. Inhaled furosemide does not alleviate respiratory effort during flow-limited exercise in healthy subjects. Pulm Pharmacol Ther 2008:21:196-200.

16. Stoller JK, Ferranti R, Feinstein AR. Further specification and evaluation of a new clinical index for dyspnea. Am Rev Respir Dis 1986;135:1129-34.

17. Miller MR, Hankinson J, Brusasco V, et al, on behalf of the ATS/ERS Task Force. Standardisation of spirometry. Eur Respir J 2005;26:319-38.

18. Wanger J, Clausen JL, Coates A, et al, on behalf of the ATS/ERS Task Force. Standardisation of the measurement of lung volumes. Eur Respir J 2005;26:511-22.

19. Crapo RO, Morris AH, Clayton PD, et al. Lung volumes in healthy non-smoking adults. Bull Eur Physiopathol Respir 1982;18:419-25.

20. Morris JF, Koski A, Temple WP, et al. Fifteen-year interval spirometric evaluation of the Oregon predictive equations. Chest 1988;92:123-7.

21. Briscoe WA, Dubois AG. The relationship between airway resistance, airway conductance, and lung volumes in subjects of different age and body size. J Clin Invest 1959:37:1279-85.

22. Jones NL. Clinical exercise testing. 3rd ed. Philadelphia: W B Saunders, 1988.

23. Borg GAV. Psychophysical basis of perceived exertion. Med Sci Sports Exerc 1982;14:377-81.

24. O'Donnell DE, Revill SM, Webb KA. Dynamic hyperinflation and exercise intolerance in chronic obstructive pulmonary disease. Am J Respir Crit Care Med 2001;164:770-7.
25. Mador MJ, Kufel TJ, Pineda L. Quadriceps fatigue after cycle exercise in patients with chronic obstructive pulmonary disease. Am J Respir Crit Care Med 2000; 161:447-53

26. Maltais F, Hamilton A, Marciniuk D, et al. Improvements in symptom-limited exercise performance over $8 \mathrm{~h}$ with once-daily tiotropium in patients with COPD. Chest 2005;128:1168-78.

27. Corboz MR, Ballard ST, Gao H, et al. Differential effects of furosemide on porcine bronchial arterial and airway smooth muscle. J Appl Physiol 2000;89:1360-4.

28. Knox AJ, Ajao P. Effect of frusemide on airway smooth muscle contractility in vitro. Thorax 1990;45:856-9.

29. Undem BJ, Kollarik M. The role of vagal afferent nerves in chronic obstructive pulmonary disease. Proc Am Thorac Soc 2005;2:355-60.

30. Schelegle ES, Green JF. An overview of the anatomy and physiology of slowly adapting stretch receptors. Respir Physiol 2001;125:17-31.

31. Sant'Ambrogio G, Widdicombe J. Reflexes from airway rapidly adapting receptors Respir Physiol 2001;125:33-45.

32. Lee L-Y, Pisarri TE. Afferent properties and reflex functions of bronchopulmonary Cfibers. Respir Physiol 2001;125:47-65.

33. Lockhart A, Slutsky AS. Furosemide and loop diuretics in human asthma. Chest 1994;106:244-9.

34. Nehashi S, Nishino T, Ide T. Inhaled furosemide inhibits behavioural response to airway occlusion in anesthetized cats. Anesthesiology 2001;95:1234-7.

35. Tryfon S, Kontakiotis T, Mavrodfridis E, et al. Hering-Breuer reflex in normal adults and in patients with chronic obstructive pulmonary disease and interstitial fibrosis. Respiration 2001;68:140-4.

36. van Lunteren $\mathbf{E}$. Attenuation of the Hering-Breuer reflex: yet another adverse consequence of COPD? Respiration 2001;68:131-2

37. Saito S, Miyamoto K, Nishimura M, et al. Effects of inhaled bronchodilators on pulmonary hemodynamics at rest and during exercise in patients with COPD. Chest 1999;115:376-82.

38. Savoy J, Dhingra S, Anthonisen NR. Inhaled lidocaine changes resting human breathing pattern. Respir Physiol 1982;50:41-9.

39. Davies A, Dixon M, Callanan D, et al. Lung reflexes in rabbits during pulmonary stretch receptor block by sulphur dioxide. Respir Physiol 1978;34:83-101.

40. Sibuya M, Kanamaru A, Homma I. Inspiratory prolongation by vagal afferents from pulmonary mechanoreceptors in rabbits. Jpn J Physiol 1993;43:669-84.

\section{BMJ Careers online re-launches}

BMJ Careers online has re-launched to give you an even better online experience. You'll still find our online services such as jobs, courses and careers advice, but now they're even easier to navigate and quicker to find.

New features include:

- Job alerts - you tell us how often you want to hear from us with either daily or weekly alerts

- Refined keyword searching making it easier to find exactly what you want

- Contextual display - when you search for articles or courses we'll automatically display job adverts relevant to your search

- Recruiter logos linked directly to their organisation homepage - find out more about the company before you apply

- RSS feeds now even easier to set up

Visit careers.bmj.com to find out more. 